\title{
Observando a indecidibilidade da participação do terceiro setor na governação em rede
}

Observing the Undecidability of Third Sector Participation in Network

Governance

En observant l'indécidabilité du tiers secteur dans la gouvernance en réseau

Sílvia Ferreira

\section{OpenEdition}

Journals

Edição electrónica

URL: http://journals.openedition.org/rccs/4955

DOl: $10.4000 /$ rccs.4955

ISSN: 2182-7435

Editora

Centro de Estudos Sociais da Universidade de Coimbra

Edição impressa

Data de publição: 1 Junho 2012

Paginação: 107-132

ISSN: 0254-1106

\section{Refêrencia eletrónica}

Sílvia Ferreira, « Observando a indecidibilidade da participação do terceiro setor na governação em rede ", Revista Crítica de Ciências Sociais [Online], 97 | 2012, colocado online no dia 19 abril 2013, criado a 19 abril 2019. URL : http://journals.openedition.org/rccs/4955 ; DOI : 10.4000/rccs.4955 


\title{
SÍLVIA FERREIRA
}

\section{Observando a indecidibilidade da participação do terceiro setor na governação em rede}

\begin{abstract}
Neste artigo analisa-se a participação do terceiro setor nas parcerias locais, estratégicas e multissetoriais que constituíram o projeto da Terceira Via para a coordenação do bem-estar social. Observa-se, a partir de um estudo de caso etnográfico, um espaço/ /tempo onde se negoceia a governação, assumindo-se como ponto de entrada o terceiro setor, que deve participar nesse projeto de governação. Mobiliza-se o aparelho conceptual da teoria luhmaniana dos sistemas sociais autopoiéticos para descrever e analisar a tentativa de um grupo de organizações do terceiro setor de desenhar uma estrutura de representação deste numa Parceria Local Estratégica, em Inglaterra. A partir da observação das decisões tomadas num conjunto de reuniões, discute-se a redução da complexidade e os paradoxos da participação do terceiro setor no modo de governação em rede.
\end{abstract}

Palavras-chave: bem-estar social; governação; Inglaterra; Terceira Via; terceiro setor; sistemas complexos.

\section{Introdução}

Desde que, na década de 1970, se deu a emergência do terceiro setor (TS) como ator nas políticas de bem-estar, a sua relevância e a variedade de papéis atribuídos não tem cessado de aumentar. Com diferenças entre os vários modelos, em muitos países o terceiro setor ganhou uma proeminência nacional ao lado das estruturas e das políticas públicas de governação do bem-estar e adquiriu uma relevância crescente na sua coordenação local. A própria noção de terceiro setor é nova e ainda amplamente discutida. Para alguns autores, este ocupa um lugar específico ao lado de outros setores como do Estado/público, do mercado/economia/privado ou da comunidade/família (e.g. Billis, 2010; Almeida, 2011), enquanto para outros se situa na intersecção destes setores, ocupando um espaço na esfera pública (Brandsen et al., 2005; Evers, 2008) capaz de articular problemas e necessidades individuais através da comunicação e de os transformar em problemas e necessidades coletivos (Caillé e Laville, 1998; Enjolras, 2001). 
Na sua diversidade, o TS ocupa um lugar paradoxal. É protagonista na perda de centralidade do Estado enquanto organizador e provedor de bem-estar, mas é também um dos principais canais de pressão para a expansão da responsabilidade pública. Além disso, veio a tornar-se parceiro do Estado na partilha de responsabilidades públicas não só pela provisão, mas também pela governação do bem-estar social. Estas alterações articulam-se com as mudanças que têm ocorrido, desde a década de 1970, ao nível das conceções e práticas sobre o papel e a forma do Estado de bem-estar e o conteúdo das políticas sociais no sentido de uma maior pluralidade de preferências sobre o modo de coordenação que deve predominar na governação do bem-estar. ${ }^{1}$

O papel do terceiro setor no bem-estar tem criado tensões na relação entre este setor e o Estado, que são expressas, por exemplo, nos debates sobre isomorfismo institucional (DiMaggio e Powell, 1983), segundo os quais as organizações do terceiro setor (OTS) tendem a assumir crescentemente características das organizações públicas. Trata-se de uma tensão que resulta da crescente assunção do caráter público dos serviços sociais fornecidos pelas OTS, à medida que estes serviços ocupam um lugar mais proeminente nas políticas sociais (Bahle, 2003) ou da contratualização do terceiro setor pelo Estado para o fornecimento destes serviços, o que traz novas exigências de produção e de prestação de contas. A orientação para a nova gestão pública no Estado, significando a incorporação de formas de gestão típicas das empresas, intensificou este controle, estendendo-o assim à relação entre o Estado e as OTS, trazendo consigo critérios de qualidade, transparência e prestação de contas. Cada vez menos o Estado se concebe como fornecedor direto e mais como promotor e regulador, estendendo, por isso, essa regulação aos serviços fornecidos pelas OTS.

Porém, ao mesmo tempo que as OTS perdem autonomia na definição do modo como produzem e prestam os serviços, a quem os prestam e mesmo onde os prestam, desenvolve-se paralelamente uma nova versão do Estado de bem-estar em torno do conceito de governação pública (Osborne, 2010). Esta tem a sua origem nos debates sobre as novas formas de governação e na ênfase sobre a presença crescente de uma maior heterogeneidade de atores na governação do bem-estar.

A chamada passagem do governo para a governação (Rhodes, 2000) evidencia as transformações do papel do Estado na governação, o esbatimento

\footnotetext{
${ }^{1}$ Estas preferências têm também expressões institucionalizadas em diferentes tipos de Estados-Providência. Para uma revisão da articulação entre as tipologias de bem-estar e regimes nacionais de terceiro setor, ver Ferreira (no prelo).
} 
das fronteiras entre os setores e um maior número e diversidade de atores e racionalidades, sendo as políticas de parceria um dos melhores exemplos. Não se quer com isto afirmar que não existissem anteriormente redes de atores sociais e múltiplas formas de colaboração entre o Estado e as OTS, com variações em diferentes países e áreas do bem-estar (Phillips e Smith, 2011). Na realidade, estas formas de colaboração estão presentes desde que o Estado assumiu a responsabilidade pelo bem-estar da população, intervindo em campos que eram anteriormente dominados pela presença destas organizações. Porém, tal como só recentemente surgiu a ideia de um terceiro setor, também só recentemente estas formas de colaboração ganharam proeminência enquanto projeto governamental específico para a governação do bem-estar, uma terceira via entre o modelo de governação dominado pelo Estado e o modelo de governação mercantil, ou uma alternativa à governação tripartida entre Estado, sindicatos e associações patronais (Lowndes e Sullivan, 2004). Este modelo, que floresceu na década de 1990, levou à intensificação das políticas públicas orientadas para estes espaços de partilha da governação com o TS.

O conceito de governação é ele próprio muito amplo e de aplicação diversa. A melhor forma de se compreender o seu significado atual é assumir a distinção de Jessop (2002) entre uma versão lata e uma versão restrita de governação. A origem do conceito de governação é encontrada na ideia de orientação (steering), no sentido de pilotar um navio. Para muitos autores, a "orientação" é feita pelo Estado, pelo estadista ou por outros atores relevantes. Mas também é usada para descrever a governação das empresas, a governação das universidades, a governação das profissões, etc. É a partir desta perspetiva lata que se pode falar de vários modos de governação, como fazem autores como Kooiman (1993) - autogovernação (desregulacão), cogovernação (redes, parcerias, cogestão, cooperação) e hierarquia (burocracia, controlo) - ou Jessop $(2002 ; 2003)$ - troca (mercado), hierarquia (Estado, empresas) e heterarquia (redes) - entre outros.

A governação, numa perspetiva restrita que corresponde ao sentido que o conceito assume atualmente, refere-se a um modo específico de coordenação de atividades complexas e interdependentes, envolvendo redes de atores estatais e não estatais (Jessop, 2002). O uso do conceito de heterarquia para designar este modo de governação em rede é particularmente adequado na medida em que descreve as articulações complexas de estruturas reticulares onde podem existir vários centros e onde estes centros se distribuem horizontalmente ou/e em hierarquias variáveis. Chama-se assim a atenção para a participação de um número alargado de atores e interessados nos processos de governação e assinala-se uma mudança nos modos de governação 
(ou coordenação), da centralidade das formas hierárquicas ou do mercado para a noção de redes, comunidade ou associação. Sørensen e Torfing propõem o conceito de governação democrática em rede:

1. uma articulação horizontal relativamente estável entre atores interdependentes mas operacionalmente autónomos; 2 . que interagem através de negociações; 3 . que têm lugar num quadro regulatório, normativo, cognitivo e imaginário; 4 . que é autorregulado no quadro dos limites estabelecidos por forças externas; e 5. que contribui para a produção de objetivos públicos. (2007: 9)

Em termos concretos, este modo de governação descreve alguns tipos de parceria, particularmente as que envolvem o Estado e o terceiro setor na prossecução de objetivos de interesse público ou coletivo. ${ }^{2} \mathrm{O}$ enfoque aqui é, pois, num tipo de parcerias que se afigura como exprimindo um novo modo de coordenação do bem-estar por parte do Estado, desenhando as condições para a governação a um nível de metagovernação (Jessop, 2003). Sublinham-se aqui as parcerias locais, estratégicas e multissetoriais criadas no contexto de políticas nacionais. Estas parcerias contribuem para a multiplicação das escalas de governação do bem-estar social ao nível subnacional - envolvendo frequentemente as autarquias e tendo por objetivo a identificação dos problemas e aspirações das populações de determinado território -, visam a mudança em direção a um horizonte coletivo futuro estabelecido a partir da coordenação dos diferentes horizontes temporais dos atores sociais envolvidos, significam uma multiplicação dos atores na governação, envolvendo um leque diverso de atores públicos e do TS e, por vezes, também lucrativos e implicam uma dupla posição no papel do Estado - de parceiro igual na governação e de metagovernador, ou seja, organizador das condições de governação (Ferreira, 2012). São exemplo destas parcerias, a Rede Social e a Agenda 21 Local, em Portugal, os Planos de Zona, em Itália, as Local Strategic Partnerships, em Inglaterra (Ferreira, 2012; Polizzi, 2012).

Nos debates sobre a governação em rede, o terceiro setor ocupa um lugar proeminente já não apenas como prestador de serviços em parceria com o Estado, mas também como participante nas decisões acerca dessa mesma provisão e, em termos mais gerais, na organização dos serviços. É este papel que aqui se procura compreender, pressupondo uma alteração no relacionamento entre o Estado e o terceiro setor. Mais do que isso,

\footnotetext{
${ }^{2}$ Existe uma grande variedade de parcerias, desde as chamadas parcerias público-privadas (PPP) (Renda e Schreffler, 2006) às parcerias locais (Rodrigues e Stoer, 2001; Sullivan e Skelcher, 2002).
} 
pretende-se assumir aqui uma compreensão da governação a partir do posicionamento do terceiro setor e não a partir do posicionamento do projeto de metagovernação do Estado. Não se trata de procurar saber se a governação em rede responde aos objetivos de governação do Estado. Trata-se de assumir as consequências metodológicas do significado de governação em rede, presumindo que não existe apenas um ponto de observação a partir do qual tudo se observa - e coordena - mas, sim, vários pontos possíveis de observação, um dos quais é o terceiro setor. Uma postura metodológica que parte das abordagens da complexidade oferece potencialidades analíticas para a compreensão da posição do terceiro setor na governação em rede a partir da posição deste. Além de mobilizar o paradigma da complexidade para compreender o terceiro setor na governação, trata-se também de incorporar analiticamente as descrições da governação como um mecanismo complexo adequado para governar as sociedades atuais, descritas como complexas.

Foi em Inglaterra, durante o governo do New Labour, que se foi mais longe no uso das parcerias como forma de governação do bem-estar, vistas como uma terceira via entre o estatismo e o neoliberalismo, e foi também neste país que mais proeminência adquiriu o terceiro setor como protagonista desta Terceira Via (Kendall e Taylor, 2010). Assim, é o elevado desenvolvimento das políticas de parceria e do TS e a sua influência internacional, por um lado, e a presença de uma ontologia da complexidade nestas políticas, por outro, que tornam o caso inglês particularmente interessante para compreender as transformações da relação entre o Estado e o terceiro setor.

Foi com base nesta exemplaridade que se adotou uma metodologia de estudo de caso alargado de cariz etnográfico (Burawoy, 1998; Evens e Handelman, 2006) de uma Local Strategic Partnership (LSP) e do terceiro setor numa localidade inglesa. Esta abordagem foi informada teoricamente por uma perspetiva da complexidade, cuja capacidade descritiva e interpretativa se foi evidenciando à medida que decorria a presença no campo através de um processo iterativo entre a pesquisa empírica e a análise teórica. A abordagem etnográfica demonstrou-se adequada para lidar com a complexidade da governação, ao permitir observar os espaços de negociação da governação e a complexidade dos processos, seguir os atores e os temas, focar as organizações e os discursos, observar processos de mudança e situar a investigação no lugar onde convergem discursos e práticas contraditórias (Ó Riain, 2009; Medd, 2002). A análise do material empírico recolhido, ao mobilizar o paradigma da complexidade a partir da perspetiva luhmaniana, permitiu reconstruir teoricamente as dimensões 
complexas da governação a partir da posição do terceiro setor na governação. Não está, pois, em causa avaliar o sucesso ou o fracasso da governação na medida em que numa perspetiva heterárquica tal implicaria questionar a posição a partir da qual se avalia o que é sucesso ou fracasso. Mas sim de perceber os paradoxos que emergem da participação do terceiro setor na governação.

Neste artigo descreve-se e analisa-se um acontecimento que exprime o reconhecimento comum de uma participação inadequada ou insuficiente do TS na governação. Trata-se de uma sequência de reuniões de OTS visando desenhar uma estrutura de representação do TS na LSP e que surge na sequência de um projeto que tem o objetivo de melhorar a participação deste setor na LSP. Estas reuniões podem ser descritas, na linha de Jarzabkowski e Seidl (2006), como episódios estratégicos cuja característica é possuírem um princípio e um fim guiados por limitações temporais e por objetivos específicos. A compreensão da importância deste conjunto de reuniões foi possível no âmbito da estratégia metodológica prosseguida, pois esta permitiu identificar a relevância de certos eventos capazes de condensar o sentido das observações e, como tal, guiar a presença no campo e a seleção dos elementos a observar.

Nas páginas seguintes começa-se por apresentar os elementos da construção do caso, aprofundando-se a descrição das Local Strategic Partnerships (LSP) enquanto governação e descrevendo-se a LSP estudada no contexto destas parcerias. Descreve-se a participação do TS na LSP e dá-se particular atenção ao que se escolheu como ponto de entrada para o terceiro setor local, o Centre for Voluntary Services. Sublinha-se a relevância do episódio em análise enquadrando-se este num espaço reflexivo do TS local sobre esta participação.

$\mathrm{Na}$ secção seguinte apontam-se os elementos principais da abordagem analítica a partir de uma perspetiva que valoriza as operações de redução da complexidade e usa elementos da perspetiva luhmaniana dos sistemas complexos como instrumentos analíticos, com particular atenção para a abordagem das organizações e das decisões. A partir daqui descrevem-se observações empíricas relativas às decisões tomadas num conjunto de reuniões que tiveram lugar num grupo de OTS para desenhar uma estrutura de representação do TS na LSP. Finalmente, retomam-se os instrumentos teóricos e conceptuais da teoria luhmaniana dos sistemas em articulação com vista a aprofundar a compreensão do caso.

O objetivo pretendido não é a generalização das conclusões empíricas do caso, mas a identificação de elementos com potencial de transferibilidade (Schofield, 2000) para a compreensão de outros casos e, muito em especial, 
exemplificar a capacidade heurística da abordagem da complexidade que aqui se adota para observar a governação não a partir da posição (standpoint) do governo mas, sim, a partir da posição (standpoint) do TS.

\section{Construindo o estudo de caso}

Como refere Ragin (1992) a construção do caso deve também ser vista como uma operação de pesquisa. A definição das unidades de observação, das fronteiras e da temporalidade da observação não pertencem ao objeto real mas, sim, à (re)construção empírica desse objeto. Tal acontece mesmo quando se trata de um objeto ontologicamente delimitado fora do estudo (ibidem) como acontece neste estudo que se centrou numa LSP e no terceiro setor, num espaço territorialmente delimitado pelas fronteiras administrativas de um município local. A presença no campo decorreu entre novembro de 2006 e novembro de 2007, acompanhando o desenvolvimento de processos em curso, nomeadamente vários episódios estratégicos relacionados com momentos de revisão e reestruturação que forneceram acesso à reflexividade dos atores sociais. De acordo com Ragin (1992), este é um caso exemplar na medida em que tanto a LSP como o terceiro setor se encontram também organizados em outras localidades inglesas, possuindo ainda alguma relação com práticas e discursos presentes em outros países. ${ }^{3}$

As Local Strategic Partnerships (LSP), criadas em 2001, constituíram uma política nacional e uma exigência colocada ao governo local e às organizações locais na forma de recomendação, orientação, ou boa prática (DETR, 2001), podendo ter consequências em termos de acesso a recursos ou de avaliação de desempenho dos municípios. Bailey (2003) descreve-as como macroparcerias, devendo incluir potencialmente todos os atores e temas relevantes num determinado território. Implicam um consenso sobre as necessidades e aspirações locais, devendo as organizações cooperar para desenvolver e implementar uma "estratégia de comunidade", e requerem o envolvimento das OTS e dos habitantes locais em condições de igualdade com outros parceiros locais públicos e privados (DETR, 2001).

A LSP observada segue de perto as características das outras LSP no país, o que denota efeitos de isomorfismo. Possui como território o equivalente ao município e um horizonte temporal de 20 anos na sua Estratégia de Comunidade. Encontra-se estruturada num grupo executivo e em grupos temáticos, organizados em subgrupos, e ainda num fórum geral de todos os parceiros, sendo na altura presidida por uma vereadora eleita pelos parceiros.

\footnotetext{
${ }^{3}$ É aqui que me distancio de Burawoy (1998), na medida em que este autor prefere a seleção de casos desviantes como forma de falsificar a teoria.
} 
Possui um pequeno orçamento proveniente do governo local para financiar projetos que concretizem a estratégia definida e é coordenada por um funcionário do município. No momento do trabalho de campo, a Estratégia de Comunidade e a estrutura da LSP encontravam-se em revisão.

$\mathrm{O}$ terceiro setor inglês encontra-se bem estruturado nacionalmente, possui uma forte identidade e amplo reconhecimento e assume uma posição proeminente nas políticas enquanto setor (Kendall e Taylor, 2010). Em 1998, no início do mandato do primeiro governo do New Labour, foi assinado um pacto de cooperação entre o governo e o TS, o Compact, que simultaneamente reconhece a variedade de papéis do TS e o constitui como parceiro do governo, tanto ao nível nacional como local. O Compact local foi concebido como uma plataforma para o desenvolvimento das relações de parceria entre o Estado e o TS, incluindo a dimensão económica e a dimensão política desta relação - a introdução desta última marca a diferença relativamente aos governos conservadores. O corolário do reconhecimento do TS foi a criação de uma Secretaria de Estado do Terceiro Setor, em 2006, que procurou articular a ideia de um só setor, incluindo o setor voluntário, o setor da comunidade, as cooperativas e as empresas sociais. Os discursos de Ed Milliband, o seu primeiro secretário de Estado, evidenciam uma conceção de setor complementar ao Estado, com uma pluralidade de papéis sociais, económicos e políticos: a) envolver e capacitar os utilizadores no fornecimento de serviços, chegar a grupos sociais a que os serviços públicos não conseguem chegar; b) introduzir a capacidade de inovar e pensar de maneira nova sobre os problemas sociais; c) ter a capacidade de falar em nome dos que não têm voz. Ao Estado cabe: a) fornecer universalidade e equidade no acesso aos serviços; b) tratar da prestação de contas através dos processos democráticos nos governos nacionais e locais (Milliband, 2006).

Nas parcerias, as OTS são vistas simultaneamente como fornecedores de serviços, participantes no desenho e implementação de políticas e representantes da comunidade local (ODPM, 2005). Johnson e Osborne (2003) descrevem a relação entre o TS e o Estado como sendo de cogovernação e coordenação. A primeira enquadra-se numa agenda de democracia participativa para corrigir a ineficácia desta e a segunda refere-se à coordenação entre o governo local, as empresas e o TS na provisão de serviços públicos, sendo também designada como nova governação pública (Osborne, 2010) ou coprodução (Brandsen e Pestoff, 2006), incluindo formulação de políticas, planeamento e fornecimento dos serviços. A combinação da cogovernação e da coordenação é uma marca da política da Terceira Via. 
O Centre for Voluntary Services (CVS) é uma organização federativa local do terceiro setor. Estas estruturas foram criadas na década de $1970^{4}$ e têm tido um papel importante na estruturação do setor e na intermediação entre este e o governo. Desempenha ainda papéis de representação e de capacitação, contribuindo para a ideia de que existe um "setor" ao nível local. ${ }^{5}$ Trata-se de um papel típico dos intermediários, os quais desempenham um papel ativo na constituição das relações que medeiam (Medd et al., 2005), funcionando igualmente como mecanismo de governação (Dunsire, 1996). É por estas razões que se selecionou esta organização para o ponto de entrada no "terceiro setor" local.

A participação do TS na LSP dá-se: a) nos grupos e subgrupos temáticos, organizações individuais, fornecedoras de serviços ou/e especialistas em áreas e públicos específicos, e b) no executivo, através do CVS, enquanto representante do setor, e de outras OTS representantes da comunidade. Tal como em muitas outras LSP (Russel, 2005), as OTS presentes são sobretudo as grandes organizações locais, estando algumas delas em mais do que um espaço - executivo, grupos temáticos ou building blocks (BB) e subgrupos. O CVS tem lugar reservado nos grupos temáticos da LSP, que não ocupa alegadamente por falta de recursos e expertise. Existe um elevado número de pequenas e médias organizações que está ausente da parceria, o que é visto como uma situação indesejável.

As redes de governação local, mesmo as formais como as parcerias, possuem fronteiras fluidas que incorporam diversas espacialidades e temporalidades, quer da parceria, quer dos parceiros. Estão também ligadas a outras redes de diferentes formas em diferentes momentos. Estão em permanente negociação acerca dos atores, temas, objetos, territórios a serem governados e mesmo sobre quem governa e quem é governado. Assim, a observação destas redes implica seguir pessoas, objetos, metáforas, histórias e conflitos à medida que se constrói o sentido da dinâmica dessas redes. A etnografia permite ao/à investigador/a "localizar-se estrategicamente em pontos críticos de intersecção, examinar diretamente a negociação entre

\footnotetext{
${ }^{4}$ A formação dos CVS deu-se em meados da década de 1970, no contexto de uma importante reorganização do poder local visando fortalecer as funções deste nas áreas dos serviços sociais, habitação e educação. Tratou-se de uma estratégia da estrutura federativa nacional destas organizações de replicar ao nível local as mesmas funções que possuía ao nível nacional (Knight, 1993: 25).

5 O Wolfenden Report, de 1973, marca a construção de uma ideia de setor, mobilizando pela primeira vez uma terminologia de setores - estatal, comercial, voluntário e informal. Foi dada relevância às organizações federadoras, designadas de organizações intermediárias, cujos papéis foram apontados como sendo de desenvolvimento das organizações, fornecimento de serviços de apoio e de recursos, ligação entre as organizações e representação do setor. Estes papéis mantiveram-se ao longo dos anos, tendo sido suportados e fortalecidos pelas políticas dos diversos governos - conservadores ou trabalhistas.
} 
atores sociais interconectados através de múltiplas escalas" (Ó Riain, 2009: 299; ver também Nadai e Maeder, 2009).

É assim que se identifica como ponto focal da observação entre o Estado e o terceiro setor na governação em rede um projeto de capacitação e reforço da ligação entre o TS e a LSP, financiado por esta e proposto pelo CVS a partir de um diagnóstico, referenciado nacional e localmente, que se concentra na necessidade de um maior e melhor envolvimento do TS na LSP. ${ }^{6}$ Este projeto inclui, entre outras atividades, a dinamização de um Hub, o qual é composto por 20 OTS, incluindo algumas das maiores organizações locais, algumas das federações subsetoriais existentes e representantes de tipos diversos de organizações. ${ }^{7} \mathrm{O} \mathrm{Hub}$ consiste basicamente numa reunião bimensal onde se discutem questões relacionadas com o TS e a sua relação com o Estado, como as políticas de parceria, as reformas nos serviços públicos ou as medidas de apoio ao TS. Outra das atividades deste projeto é a organização de um Fórum do TS, que consiste em quatro encontros anuais abertos a todas as OTS, para os quais são convidados conferencistas que abordam temas que preocupam as organizações e criam oportunidades de interação entre elas (por exemplo exposição de projetos, oficinas, consultas, etc.).

O CVS tem vindo a promover uma lógica de rede como forma de governação do setor local, estando na origem da criação, promoção e coordenação de redes e encontros, de que o Hub e o Fórum são exemplos. Percebe-se que o CVS já não é suficiente para a representação do setor na LSP, como é assumido quer pelo CVS, quer por outras OTS. Isto acontece porque a presença na coprodução de políticas implica uma expertise em relação aos problemas, aos clientes e às práticas que o CVS não tem e porque a crescente diversificação e complexificação do TS local põe em causa a identidade do setor. As políticas governamentais de apoio ao desenvolvimento da chamada infraestrutura do TS têm também contribuído para a diversidade de organizações que podem desempenhar alguns dos papéis do CVS.

É este aspeto crucial que permite não só identificar o trabalho do Hub, mas também a sua relevância para a compreensão da relação entre o terceiro setor e a LSP.

\footnotetext{
${ }^{6}$ A informação e o acesso a este projeto deram-se na sequência da primeira reunião com o CVS, perante a constatação mútua de que as questões de pesquisa tinham semelhança com os objetivos do projeto.

7 Como as organizações prestadoras de serviços e de advocacia na área da igualdade e diversidade, saúde mental, exclusão social e aconselhamento, sustentabilidade, idosos, jovens, mulheres, cuidadores, sem-abrigo, organizações de áreas rurais e centros comunitários.
} 


\section{Sistemas sociais e decisões}

O diagnóstico da necessidade da governação em rede em sociedades complexas encontra sustentação na ideia de uma crescente fragmentação e complexidade das sociedades, levando ao desaparecimento de um centro - frequentemente o Estado nacional - a partir do qual a sociedade pode ser coordenada. É notório o paralelismo desta descrição com a das sociedades funcionalmente diferenciadas (Luhmann, 2002). Para Luhmann (1995; 2006), as sociedades contemporâneas são caracterizadas pela diferenciação funcional, distinguindo-se pela coexistência de sistemas autopoiéticos, nenhum dos quais capaz de determinar totalmente as operações de outro sistema. $\mathrm{Na}$ governação, enfatiza-se a sua característica capacidade de autorregulação e preferem-se políticas que criem as condições para a autogovernação das sociedades. Morçöl (2005) encontra paralelismos entre a governação em rede e as noções de complexidade: auto-organização e autorreferencialidade, ausência de um centro e propriedades emergentes, estabilidade e dinamismo simultâneos, multiplicidade de atores e interações, fluidez de estruturas, perceções e preferências dinâmicas dos atores, construção social das redes e acerca das redes, gestão implicando a cogovernação, steering, coprodução e flexibilidade.

Existem dois modos possíveis de abordar a complexidade da governação. Um, que procura dar conta dessa mesma complexidade, em que se privilegiam conceitos e teorias que permitam perceber os sistemas complexos (Byrne, 1998). Outro, que parte de uma ontologia da complexidade para observar os processos de redução de complexidade. Segundo esta perspetiva qualquer comunicação, sistema ou observação implica uma redução da complexidade do mundo (Geyer e van der Zowen, 2001). De acordo com Luhmann (1995), os sistemas são mecanismos de redução da complexidade e as suas operações são operações de redução da complexidade. O paradoxo da complexidade é que as operações de redução da complexidade aumentam a complexidade, pois cada seleção cria a sua própria contingência (Luhmann, 1995). É esta perspetiva que aqui se adota, recorrendo aos instrumentos conceptuais e analíticos da teoria luhmaniana dos sistemas complexos.

Para Luhmann $(1995$; 2006), todos os sistemas sociais são sistemas de comunicação, distinguindo-se, por isso, de outros tipos de sistemas como os psíquicos (consciência) ou os biológicos. Os vários tipos de sistemas sociais são: a sociedade, a interação, os movimentos sociais, as organizações e os sistemas funcionais (educação, saúde, economia, direito, religião, etc.).

Todos os sistemas possuem um fechamento autopoiético específico que os distingue do seu ambiente e que é condição básica para as suas possibilidades de comunicação com o ambiente (Clarke e Hansen, 2009). Esta comunicação 
processa-se através dos acoplamentos estruturais, que consistem em "uma relação mútua ou correspondência entre a estrutura de uma unidade e a estrutura do seu ambiente (incluindo outras unidades no ambiente)" (Mingers, 2002: 293). Assim, a relação dos sistemas com o ambiente é sempre seletiva, na medida em que ao recolher deste o que necessitam para a continuação das suas operações apenas recolhem o que as suas operações autopoiéticas permitem recolher. De nada serve se o sistema de saúde procurar comunicar em termos de doença/não doença se o sistema que recebe a comunicação apenas compreender comunicações pagar/não pagar. As comunicações dos outros sistemas no ambiente tornam-se, assim, irritações às quais o sistema pode ou não responder estabelecendo acoplagens (Hutter e Teubner, 1993). Por exemplo, se a doença de um trabalhador for vista como implicando prejuízos económicos para as empresas.

As organizações e os programas são os dois modos através dos quais um sistema pode ressoar em outro sistema. Porque são o único tipo de sistema que pode comunicar com o ambiente, as organizações asseguram a comunicação entre os sistemas e o ambiente. Os elementos das organizações são: membros, canais de comunicação, programas e decisões (Seidl, 2005; Andersen, 2008). As operações autopoiéticas das organizações são decisões que se ligam a decisões que se ligam a outras decisões e que têm como premissas de decisão os elementos das organizações. As decisões podem criar acoplamentos estruturais, produzindo decisões que usam os códigos e os meios de comunicação de diferentes sistemas (Andersen, 2008). Algumas organizações estão acopladas dominantemente a um sistema, como os tribunais ao sistema legal, outras estão acopladas a mais do que um sistema, como as universidades aos sistemas científico e educativo, e outras, como os sindicatos e as OTS, não estão acopladas a nenhum sistema em particular (Luhmann, 2006).

O paradoxo da complexidade reproduz-se na decisão através do paradoxo da indecidibilidade, no sentido em que uma decisão para ser realmente decisão tem de implicar que a decisão alternativa é igualmente válida. ${ }^{8} \mathrm{Como}$ afirmam Seidl e Becker (2006), a comunicação de uma decisão comunica também as decisões alternativas que podiam ter sido tomadas e não foram. Torna-se, por isso, necessário deslocar para um lugar invisível o paradoxo das decisões.

As decisões baseiam-se em premissas de decisões - decisões passadas e estas são importantes para resolver o paradoxo das decisões. A escolha

\footnotetext{
${ }^{8} \mathrm{O}$ paradoxo acontece quando as condições de possibilidade de algo implicam também a sua impossibilidade.
} 
de uma decisão pode ser justificada com base em premissas de decisões decidíveis - decisões que se podem decidir - ou de decisões indecidíveis - decisões não assumidas como decisões, como quando se atribuem decisões a decisões passadas (ou futuras) ou em outros espaços. Os elementos das organizações são todos eles premissas de decisões (a falta de pessoal, o chefe, a reunião da assembleia, o plano de ação) sendo também o resultado de decisões.

De seguida identificam-se as decisões tomadas em reuniões de decisão do Hub com o objetivo de conceber uma estrutura representativa do terceiro setor local na LSP. Interpretam-se estas reuniões como um sistema de interação. A autopoiese dos sistemas de interação ocorre através do código presente/ausente. Por isso, estar presente significa participar nas operações de comunicação e, portanto, quem quer que esteja presente, mesmo que não fale, compreende (Luhmann, 2006).

A remissão das decisões das organizações para as reuniões é uma forma de lidar com a indecidibilidade das decisões na medida em que, dado o fechamento autopoiético dos sistemas, nem todas as comunicações que decorrem na interação passam para a organização. As atas das reuniões onde se condensam as decisões tomadas em cada reunião podem então ser vistas como mecanismos de acoplagem entre a interação e a organização. Os documentos preparatórios das reuniões podem ser vistos como premissas de decisão, cuja decidibilidade pode ou não ser objeto de discussão.

\section{Decidindo sobre a governação}

$\mathrm{Na}$ análise que se segue não se discute qual a melhor representação do setor mas, sim, as seleções implicadas nas decisões do TS sobre uma participação representativa. ${ }^{9}$ Identificaram-se cinco decisões principais durante quatro reuniões do $H u b,{ }^{10}$ algumas explicitamente enunciadas nas reuniões e atas e outras percebidas através da observação do que não é decidido ou é excluído das premissas de decisão decidíveis ou indecidíveis.

\section{Decidir entre a rede e a organização}

Para a primeira decisão, dois modelos de organização do TS foram colocados à discussão pela coordenação do Hub: um modelo horizontal e flexível, baseado em reuniões periódicas e eventos de networking para todo

\footnotetext{
${ }^{9}$ Como nota Russel (2005), nas LSP a questão da representatividade que se coloca ao TS não se coloca nem no caso dos parceiros do Estado nem no dos parceiros da economia.

${ }_{10}$ Decorridas entre janeiro e junho de 2007. Estive nestas reuniões como participante da interação, sendo referenciada nas atas de reunião e tendo recebido a mesma documentação que os restantes membros. Além disso, conversei informalmente com os membros acerca das decisões.
} 
o TS, e outro consistindo numa estrutura de dois pilares, com um grupo diretor, grupos temáticos existentes ou a criar e um fórum de todas as organizações. Um documento preparatório elaborado pela coordenadora das reuniões - após consulta sobre modelos de participação do TS em outras LSP - identificara os dois modelos bem como algumas vantagens e desvantagens. Os participantes consideraram que a estrutura de dois pilares permitia ter voz, participar no planeamento e envolver-se na LSP, e ainda uma maior credibilidade e legitimidade para os representantes do TS na LSP. Porém, exigia uma "mudança cultural" para o compromisso com o trabalho em parceria, que muitas organizações não estão interessadas em efetuar.

A estrutura escolhida, de dois pilares, torna mais clara a identificação dos atores, das suas relações e dos seus papéis. O controlo é colocado no grupo diretor, composto por representantes que são eleitos nos eventos do Fórum, sendo também representantes na LSP. O grupo é responsável por organizar os eventos do Fórum, "guiar o setor estrategicamente" e prestar contas ao Fórum acerca da participação na LSP. Os representantes na LSP devem incluir membros de federações e redes locais, cujo papel será o de fornecer expertise à LSP, consultando e prestando contas ao Fórum e às organizações associadas aos fóruns ou grupos temáticos existentes.

A estrutura escolhida assemelha-se à estrutura da LSP. Entre os participantes na discussão, os que têm assento na LSP enquanto representantes de OTS foram os que mais defenderam esta estrutura.

\section{Decidir sobre as estruturas de governação preexistentes}

A estrutura escolhida implica um maior grau de organização formal, processos de identificação de membros e de canais de comunicação. As decisões seguintes denotam a tentativa de organizar a complexidade do modelo em discussão, o que exige mais seleções. Isso inclui decisões sobre: o papel a desempenhar pelo CVS, o papel do Hub, o que fazer com as OTS que já estão presentes na LSP, o papel do Fórum já existente e como garantir que as redes temáticas existentes no TS sejam eleitas como representantes no Fórum. A decisão tomada foi que o CVS administra e organiza o Fórum, fornece orientação e informação, organiza a representação da comunidade e do setor e encoraja a participação no Hub e no Fórum. O Hub nomeia representantes para a LSP, funciona como grupo de pressão no interesse do setor, e fornece a infraestrutura de consulta entre o setor estatal e o TS. O Fórum promove a ligação em rede e a partilha de informação, recebe relatórios do $H u b$, nomeia ou elege os membros do Hub e é a infraestrutura de consulta do setor. 
A tensão presente na ideia de o Fórum eleger os membros do Hub, dado que põe em causa os atuais papéis e organizações nas redes do TS e na LSP, foi deslocada para o futuro, "quando o Fórum estiver mais estável".

\section{Decidir sobre o que representar e sobre a acoplagem à LSP}

A terceira reunião lidou com opções para representação do Fórum no grupo diretor e tornou visível a complexidade do TS local e a necessidade de fazer seleções. Surgiram três opções mutuamente exclusivas para decisão sobre o modo como o TS poderia ser representado na LSP:

1) Representação não temática, através da presença do coordenador e de outros membros do Hub cooptados para os grupos temáticos da LSP. Num exemplo recolhido de uma LSP de outra localidade para ilustrar esta possibilidade, as organizações foram agrupadas numa lógica que tem sobretudo em conta as suas características organizacionais e as suas culturas como: organizações voluntárias, interesses dos jovens, agências de desenvolvimento local, grupos da comunidade, comunidades religiosas e um grupo apontado como residual com desporto, arte, música, cultura e militância;

2) Representação temática coincidindo com os temas da LSP, que são: proteção civil e segurança, saúde e bem-estar, aprendizagem ao longo da vida, igualdade e diversidade, sustentabilidade ambiental, crianças e jovens, e economia;

3) Representação temática de acordo com as áreas em que o TS é descrito no Diretório das OTS locais, elaborado pelo CVS, que inclui, por exemplo: comunidade, rural, deficiência, idosos, saúde mental, habitação e sem-abrigo, crianças e jovens, ambiente, minorias étnicas, organizações de aconselhamento e apoio, droga e álcool, apoio às famílias, ex-prisioneiros.

As três seleções ilustram os dilemas da redução da complexidade do TS. Em primeiro lugar, a escolha entre representar o TS enquanto composto por organizações ou por temas de atuação. A lógica não temática significa que são os interesses organizacionais que prevalecem, em particular os que se relacionam com a sobrevivência económica das organizações, algo que alguns participantes consideram ser comum a todas as OTS, justificando esta opção. Todavia, a LSP exige mais do que isso, pois o TS deve participar na construção de políticas e projetos para a qualidade de vida da população local. A representação organizacional não consegue dar conta da atuação das organizações ao nível das suas agendas temáticas, cria dificuldades em termos de expertise, e implica falta de credibilidade na LSP e menor legitimidade na estrutura de representação para o próprio setor. 
Assim, a representação temática é preferida, pois reflete o trabalho de organizações e redes existentes, ainda que tenha também o problema de existirem organizações que atuam em vários temas e outras que não se organizam por temas ou grupos sociais, como as organizações rurais ou as organizações comunitárias.

A quarta decisão é sobre a acoplagem aos temas da LSP. A opção pela representação temática implica também a decisão sobre a seleção dos temas a representar e torna visível o desajustamento entre a variedade temática do TS e a da LSP. Considerou-se que a diferenciação existente na LSP é inadequada e resulta de prioridades que são estabelecidas não ao nível local mas, sim, pelo governo nacional, criando um risco de exclusão das organizações e de reforçar as próprias lacunas na LSP, ainda que trouxesse mais credibilidade ao TS na LSP. A não adaptação à LSP e a preservação da variedade interna também é considerada uma forma de lidar com a volatilidade da política. Além disso, uma representação de acordo com os temas do TS teria maior capacidade de mobilizar o setor para a LSP, mas tornaria mais opaca para a LSP a representação do TS nas diferentes áreas temáticas.

As duas escolhas da representação temática do TS e da LSP aparecem para decisão como mutuamente excludentes, dado que os sistemas não se observam de modo a acomodar a respetiva complexidade organizada. A LSP é aceite como uma premissa de decisão à qual o TS se deve adaptar.

\section{Decidir sobre a participação na LSP}

Antes da quarta reunião, a coordenação do Hub solicitou uma reunião à coordenação da LSP para discutir a questão da representação do TS. Porém, a coordenação da LSP adiou esta reunião para um futuro indeterminado, para quando a estrutura da LSP, então em revisão, estivesse finalizada, o que excluiu a possibilidade de o TS influenciar a estrutura temática da LSP.$^{11} \mathrm{Na}$ sequência disto, o desenho da estrutura de representação foi abandonado pelo $H u b$. Em alternativa, e sob proposta da coordenação do $H u b$, verificou-se uma mudança de estratégia em relação ao acoplamento a privilegiar: um Consórcio do TS existente a uma escala regional que visa aumentar a capacidade das organizações de concorrerem conjuntamente aos contratos públicos de fornecimento de serviços, tendo resultado de um programa público de capacitação da infraestrutura do setor para a participação nas parcerias e no fornecimento de serviços públicos (ChangeUp).

${ }^{11}$ Esta exclusão também deve ser vista à luz da pressão então exercida pelo governo central para uma maior acoplagem das LSP às políticas nacionais e uma "maior eficácia" das LSP (Geddes, 2008). 
Assim, ao nível local, manteve-se a estrutura de rede do Fórum já em funcionamento, com o papel de "celebrar" o trabalho do TS, aumentar a unidade e o apoio mútuo, encontrar e partilhar valores comuns, estabelecer redes e difundir informação e aprendizagem conjunta sobre as suas acoplagens à escala regional. O TS retira-se da participação na governação local através da LSP. Confrontada com esta autoexclusão, a LSP local iniciou um processo de análise de stakeholders para escolher as OTS que deviam participar na LSP.

\section{Interações, organizações e sistemas funcionais na governação}

Pode resumir-se o caso descrito como uma tentativa fracassada de um sistema autopoiético de estabelecer acoplagens a outro sistema através de uma estrutura representativa. É um exemplo do fechamento das redes como resultado da autorreferencialidade dos sistemas (Messner, 1997) ou dos atores (Schaap, 2007). O fechamento transparece nas discussões do Hub na medida em que observa a LSP a partir das suas próprias estruturas de observação e reflete sobre as dificuldades de acoplagem com a LSP. Por outro lado, as irritações do TS não chegam a ter ressonância na LSP, num momento em que, paradoxalmente, a revisão em curso a torna ainda mais fechada porque elimina pontos de contacto possíveis entre a LSP e o TS - dando sentido à ideia de que a autopoiese dos sistemas é condição necessária para a comunicação com o seu ambiente.

Torna-se também evidente que se está perante um sistema que se auto-observa enquanto sistema e se pretende representado na LSP enquanto tal. Torna-se, pois, importante distinguir entre as organizações individuais - integradas na LSP - e um terceiro setor que só enquanto setor se assume como parceiro do Estado.

A partir dos elementos empíricos destas reuniões e de outros dados da observação aprofunda-se agora a análise do terceiro setor na governação tomando como ponto de partida vários tipos de sistemas e mostrando como estes podem ser mobilizados na análise da participação do TS na governação em rede.

Selecionadas as reuniões acima descritas como fenómenos críticos que condensam os elementos da observação realizada ao longo do trabalho de campo, efetua-se agora uma interpretação à luz do aparelho conceptual referido.

\section{Interações e decisões}

A coordenação na governação em rede ocorre através do diálogo (Jessop, 2002) e este decorre frequentemente em espaço de reuniões onde os diferentes atores interagem face a face no sistema de interação. A centralidade 
da interação nas parcerias (Kooiman, 1993) está patente na importância que as reuniões têm na tomada de decisões ou outros aspetos por vezes evidenciados como, por exemplo, o papel de determinadas pessoas.

As reuniões são concebidas como espaço onde a negociação tem lugar e se pode chegar a acordo, um aspeto central da governação em rede. Todavia, o fechamento autopoiético significa que o que chega à organização não é a interação mas, sim, o resultado da interação na forma de decisões. Deste modo, a indecidibilidade das decisões - que outras decisões se podiam ter tomado, que atores influenciaram as decisões - fica oculta no sistema de interação.

Decisões sobre participação na governação por parte das OTS são também tomadas a jusante das reuniões, constituindo-se como premissas de decisões indecidíveis, através da ausência de organizações destas reuniões - por motivos de não afiliação ou por absentismo. ${ }^{12}$ Não participando nas reuniões, a maioria das organizações locais não participa nas decisões. O que é problemático quando o que está em causa é a representação do TS.

A caixa negra da interação em reuniões de decisão ajuda também a compreender o facto de alguns dos representantes de OTS na LSP terem participado nas decisões do Hub, mas não terem estabelecido a comunicação entre os dois sistemas nem terem criado a possibilidade de tornar o TS observável para a LSP.

\section{Organizações e redes}

As reuniões permitiram observar o desenho de uma organização, incluindo decisões sobre membros, sobre canais de comunicação e sobre as decisões pelas quais esta estrutura representativa seria responsável. Evidencia-se uma tensão entre uma tradição de estruturação do setor que privilegia formas horizontais, marcadas sobretudo por encontros entre as OTS onde a identidade enquanto setor é reforçada através do interconhecimento e, portanto, com uma forte ênfase na interação, e a estrutura de caráter mais vertical que se afigura como mais orientada para a capacidade de ter influência política, participar nas políticas de parceria e ver reconhecida uma maior legitimidade.

A tensão entre rede e organização é evidente nas tomadas de decisão do $H u b$ no que diz respeito à representação na LSP e é, de certa forma, uma característica recorrente no que se refere ao funcionamento destes mecanismos de governação sustentados nas duas ideias de diálogo para atingir consenso e na necessidade de eficácia no que diz respeito a dar sequência às decisões. A primeira forma não oferece os acoplamentos necessários

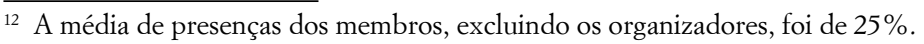


para a participação política nos termos em que é concebida na LSP, mas corresponde à cultura local do setor. A segunda forma, sendo descrita como a mais eficaz no que diz respeito à participação na decisão política, significa uma maior governação do setor, quer interna, quer pela LSP (o que fica evidente na segunda decisão).

Porém, a LSP é também ambígua. Bommes e Tacke (2005) argumentam que nas redes, ao contrário das organizações, a representação não é possível pois elas funcionam sob uma lógica de "endereçamento", em que os membros são escolhidos de acordo com as suas características e não segundo critérios gerais. Esta lógica corresponde aos critérios através dos quais foram escolhidos os membros, contribuindo para a perceção geral de que a participação do TS na LSP não é a mais adequada, mas também tornando evidentes as dificuldades de encontrar a forma adequada de representatividade ou mesmo de saber o que representar ${ }^{13}$ - como se verifica na terceira decisão.

Por fim, o Hub é um bom exemplo da proeminência crescente da governação em rede dentro do próprio TS, articulada com a forma organizacional do CVS. Não se trata, pois, de substituir as organizações por redes, mas de combinações complexas de elementos das duas formas de organização. Assim, o Hub pode ser visto como uma rede com a qual o CVS partilha a governação local do setor.

\section{Organizações e sistemas funcionais}

Como já se referiu, as OTS são um tipo de organização que não participa em sistemas funcionais específicos. Esta característica é confirmada pela relevância que a semântica do TS atribui à questão da autonomia e independência e pela diversidade de acoplagens com diferentes sistemas que lhe fornecem a sua variedade, conforme se verifica nas discussões sobre o caráter híbrido do TS. Esta variedade é um dos elementos mais valorizados para a participação do TS na LSP, mas não pode ser acolhida quando se quer estabelecer acoplagens com a LSP, como bem demonstra a quarta decisão.

No que diz respeito às relações com diferentes sistemas funcionais, o modo como a LSP se oferece à observação condiciona a perceção das OTS em relação às possibilidades de ressonância e acoplagem com a LSP e explica também o desinteresse que a LSP suscita junto de muitas OTS. Por exemplo, se as organizações não veem possibilidades de acoplagem

${ }_{13}$ A LSP combina elementos de organização e elementos de rede, uma característica que é apontada por Lowndes e Skelcher (1998) como estando presente neste tipo de parcerias, cuja estrutura varia no tempo e no espaço (Lowndes e Skelcher, 1998). 
com a LSP, não despendem energia e recursos a observar a LSP e, portanto, não se envolvem no $H u b$ ou em outros momentos de interação entre a LSP e o TS. Além disso, não basta determinado problema ser observado pela LSP. O sistema funcional que o observa pode também não produzir ressonância nas OTS. Por exemplo, uma observação da habitação a partir do sistema de saúde não tem ressonância numa organização que observa a habitação a partir da exclusão social dos sem-abrigo.

A semântica das parcerias e a agenda da Terceira Via para o TS trouxeram a observação deste pelo sistema político contrapondo-a a observações anteriores dominantemente económicas, típicas dos governos conservadores. $\mathrm{Na}$ LSP, as OTS devem participar nas decisões políticas sobre as necessidades locais e a forma de as resolver. As considerações relativas à estrutura de representação nas reuniões de decisão do $H u b$ mostram que a LSP é vista como uma forma de acoplagem ao sistema político, na medida em que se discute a maior capacidade de influência do TS e a maior participação nas decisões políticas. Porém, a decisão final regressa ao sistema económico nas considerações sobre as vantagens da acoplagem ao Consórcio no acesso a recursos.

Por outro lado, este tipo de parcerias desafia as autodescrições do TS no sistema político, sobretudo da sua acoplagem aos movimentos sociais, onde se construiu uma parte importante da semântica do TS enquanto sociedade civil. ${ }^{14} \mathrm{~A}$ governação requer as duas posições por parte do TS em relação ao Estado: tem que estar fora, representando a sociedade civil, e estar dentro, participando na cogovernação. A LSP oferece ao TS uma reentrada do TS do lado do governo, o que cria resistência entre as OTS, particularmente num contexto onde persiste uma semântica de setor como vigilante de políticas, atuando nas falhas da provisão pública, e monitor do governo local em nome da comunidade local ou de grupos e problemas específicos. Assim se compreende também que uma das razões invocadas para a última decisão foi a preferência por formas tradicionais de participação na política.

\section{Conclusão}

Neste texto, discutiu-se o lugar do terceiro setor na governação em parcerias multissetoriais, locais e estratégicas desenhadas a partir do Estado, como metagovernador e com objetivos de interesse público. Assumiu-se como ponto de entrada para a observação e análise, não o projeto de governação

\footnotetext{
${ }^{14}$ Estes são, segundo Luhmann (2006), sistemas que tematizam problemas da diferenciação funcional (sobretudo desigualdades e destruição ambiental), se orientam para o sistema político e assentam numa ficção de estarem fora da sociedade criticando a sociedade para o bem da sociedade.
} 
do governo mas, sim, a posição do TS que deve participar neste projeto. Para isso, focou-se um conjunto de reuniões de decisão que ocorreram num grupo de OTS orientado para o desenho de um mecanismo de acoplagem entre o TS e a LSP numa localidade inglesa. Teve-se, pois, acesso a um ponto de observação que permitiu observar as auto-observações do setor.

Articularam-se instrumentos analíticos da teoria dos sistemas sociais complexos de Luhmann no processo iterativo entre a teoria e a pesquisa empírica etnográfica, demonstrando a adequabilidade quer da etnografia, para a observação da governação no lugar onde ela se negoceia, quer das abordagens da complexidade para a compreensão do TS e do seu lugar na governação em rede. Focaram-se as decisões tomadas e a sua indecidibilidade resultante da necessidade de selecionar a partir da complexidade do TS para desenhar uma estrutura de acoplagem do TS à LSP.

A oportunidade de observação destas reuniões foi um resultado das potencialidades da metodologia etnográfica para acompanhar a fluidez da governação local e identificar espaços e momentos críticos, mas a compreensão do seu significado e relevância em contexto da multiplicidade de eventos e observações possíveis resulta da articulação iterativa entre empiria e teoria. Analisar o evento descrito a partir do enquadramento dos sistemas da interação, das organizações e dos sistemas funcionais permite discutir o lugar que o TS ocupa na governação.

Observaram-se os processos de redução da complexidade na tomada de decisões para retirar conclusões mais gerais acerca dos processos de governação em rede e do TS. A análise permitiu perceber dois paradoxos principais. No primeiro paradoxo, verifica-se que o TS tem de representar o outro lado do governo enquanto parceiro e, ao mesmo tempo, estar do lado do governo como corresponsável pela governação. No segundo paradoxo observa-se que a semântica da governação em parcerias necessita da variedade do TS mas, ao mesmo tempo, não tem capacidade de acolher esta mesma variedade. A presença do TS na LSP verifica-se de forma individualizada ou através de uma análise dos stakeholders, i.e., selecionados a partir da própria LSP.

Para concluir, retoma-se aqui a descrição das sociedades capitalistas avançadas enquanto funcionalmente diferenciadas como uma autodescrição destas sociedades. Sob esta perspetiva, são evidentes as convergências entre as descrições da governação em rede e a das sociedades funcionalmente diferenciadas como sistemas autónomos, interdependentes e horizontalmente relacionados. Isto leva a pensar a governação em rede como um modelo do sistema dentro do sistema social e abre a possibilidade heurística de explorar este paralelismo concebendo os paradoxos da governação em 
rede como sendo, em larga medida, os mesmos de sociedades funcionalmente diferenciadas.

\section{Referências bibliográficas}

Almeida, Vasco (2011), As Instituições Particulares de Solidariedade Social - Governação e terceiro sector. Coimbra: CES/Almedina.

Andersen, Niels Åkerstrøm (2008), Partnerships: Machines of Possibility. Bristol: Policy.

Bahle, Thomas (2003), "The Changing Institutionalization of Social Services in England and Wales, France and Germany: Is the Welfare State on the Retreat?", Journal of European Social Policy, 13(1), 5-20.

Bailey, Nick (2003), "Local Strategic Partnerships in England: the Continuing Search for Collaborative Advantage, Leadership and Strategy in Urban Governance", Planning Theory and Practice, 4(4), 443-457.

Billis, David (org.) (2010), Hybrid Organizations and the Third Sector. Challenges for Practice, Theory and Policy. Basingstoke: Palgrave Macmillan.

Bommes, Michael; Tacke, Veronika (2005), "Systems and Networks: Competing Theories or Complementary Social Structures?” in David Seidl e Kai Helge Becker (orgs.), Niklas Lubmann and Organisation Studies. Frederiksberg: Copenhagen Business School Press, 282-304.

Brandsen, Taco; Pestoff, Victor (2006), "Co-production, the Third Sector and the Delivery of Public Services: An Introduction”, Public Management Review, 8(4), 493-501.

Brandsen, Taco; van de Donk, Wim; Putters, Kim (2005), "Griffins or Chameleons? Hybridity as a Permanent and Inevitable Characteristic of the Third Sector", International Journal of Public Administration, 28(9), 749-765.

Burawoy, Michael (1998), "The Extended Case Method", Sociological Theory, 16(1), 4-33.

Byrne, David (1998), Complexity Theory and the Social Sciences. Abingdon: Routledge.

Caillé, Alain; Laville, Jean-Louis (orgs.) (1998), "Présentation", Revue du MAUSS, 11. Versão eletrónica, consultada a 07.08.12, em http://www.revuedumauss.com. fr/Pages/S11.html.

Clarke, Bruce; Hansen, Mark B. N. (orgs.) (2009), Emergence and Embodiment: New Essays on Second-Order Systems Theory. Durham: Duke University.

DETR - Department of the Environment, Transport and the Regions (2001), Local Strategic Partnerships: Government Guidance. London: DETR.

DiMaggio, Paul J.; Powell, Walter W. (1983), "The Iron Cage Revisited: Institutional Isomorphism and Collective Rationality in Organizational Fields", American Sociological Review, 48(2), 147-160. 
Dunsire, Andrew (1996), “Tipping the Balance: Autopoiesis and Governance”, Administration E Society, 28(3), 299-334.

Enjolras, Bernard (2001), L'économie solidaire et le marché: modernité, société civile et démocratie. Paris: L'Harmattan.

Evens, Terry M. S.; Handelman, Don (orgs.) (2006), The Manchester School: Practice and Ethnographic Praxis in Anthropology. Oxford: Berghahn.

Evers, Adalbert (2008), "Hybrid Organizations: Background, Concepts, Challenges”, in Stephan Osborne (org.) The Third Sector in Europe: Prospects and Challenges. Oxon: Routledge, 279-292.

Ferreira, Sílvia (2012), "Governance and Failure in Local Strategic Multi-Sectoral Partnerships: The Cases of LSP (England) and Rede Social (Portugal)”, in Emanuela Bozzini e Bernard Enjolras (orgs.), Governing Ambiguities: New Forms of Local Governance and Civil Society. Baden-Baden: Nomos, 39-56.

Ferreira, Sílvia (no prelo), "Terceiro sector e Estado-Providência em Portugal”, in Filipe Carreira da Silva (org.), Os Portugueses e o Estado-Providência. Lisboa: Imprensa de Ciências Sociais.

Geddes, Mike (2008), "Government and Communities in Partnerships in England: The Empire Strikes Back?” in Mark Considine e Sylvain Giguère (orgs.), The Theory and Practice of Local Governance and Economic Development. Basingstoke: Palgrave Macmillan, 100-125.

Geyer, Felix; van der Zowen, Johannes (2001), "Introduction to the Main Themes in Sociocybernetics", in Felix Geyer e Johannes van der Zouwen (orgs.), Sociocybernetics: Complexity, Autopoiesis, and Observation of Social Systems. Westport: Greenwood, 1-16.

Hutter, Michael; Teubner, Gunther (1993), “The Parasitic Role of Hybrids”, Journal of Institutional and Theoretical Economics, 149, 706-715.

Jarzabkowski, Paula; Seidl, David (2006), "Meetings as Strategizing Episodes in the Social Practice of Strategy", AIM Research Working Paper Series, 37. London: Advanced Institute of Management Research.

Jessop, Bob (2002), The Future of The Capitalist State. Cambridge: Polity.

Jessop, Bob (2003), "Governance and Metagovernance: On reflexivity, Requisite Variety, and Requisite Irony", in Henrik P. Bang (org.), Governance as Social and Political Communication. Manchester: Manchester University Press, 142-172.

Johnson, Carole; Osborne, Stephen P. (2003), “Local Strategic Partnerships, Neighbourhood Renewal, and the Limits to Co-Governance", Public Money \& Management, 23(3), 147-154.

Kendall, Jeremy; Taylor, Marilyn (2010), "On the Interdependence between Politics and Policy in the Shaping of English Horizontal Third Sector Initiative", in Benjamin Gidron e Michal Bar (orgs.), Policy Initiatives towards the Third Sector in International Perspective. Londres: Springer, 189-212. 
Knight, Barry, (1993), Voluntary Action, London: Home Office.

Kooiman, Jan (org.) (1993), Modern Governance: New Government-Society Interactions. London: Sage.

Lowndes, Vivien; Skelcher, Chris (1998), “The Dynamics of Multi-organizational Partnerships”, Public Administration, 76, 313-333.

Lowndes, Vivien; Sullivan, Helen (2004), "Like a Horse and Carriage or a Fish on a Bicycle: How Well do Local Partnerships and Public Participation go Together?”, Local Government Studies, 30(1), 51-73.

Luhmann, Niklas (1995), Social Systems. Stanford: Stanford University Press.

Luhmann, Niklas (2002), "Limits of Steering", in Craig J. Calhoun; Joseph Gerteis; James Moody; Steven Pfaff e Indermohan Virk (orgs.), Contemporary Sociological Theory. Oxford: Blackwell, 139-152.

Luhmann, Niklas (2006), La sociedad de la sociedad. Cidade do México: Editorial Herder. Medd, Will (2002), "Complexity and the Social World", International Journal of Social Research Methodology, 5(1), 71-81.

Medd, Will; Marvin, Simon; Bowd, Richard (2005), Researching Inbetweeness: Understanding the Transformative Role of Intermediaries. Manchester: Centre for Sustainable Urban \& Regional Futures/University of Salford.

Messner, Dirk (1997), The Network Society: Economic Development and International Competitiveness as Problems of Social Governance. London: Routledge.

Milliband, Ed (2006), "Changing Lives, Changing Society", Hinton Lecture. Consultado a 28.12.2012, em http://www.cabinetoffice.gov.uk/media/cabinetoffice/corp/assets/ publications/speeches/milibande/rtf/hinton.rtf.

Mingers, John (2002), “Can Social Systems be Autopoietic? Assessing Luhmann's Social Theory”, The Sociological Review, 50, 278-299.

Morçöl, Göktuğ (2005), "Networks and Complexity: Prospects and Challenges for a Theory of Metropolitan Governance". Comunicação apresentada no $1^{\text {st }}$ International Workshop on Complexity and Policy Analysis, University College Cork, Irlanda, 22-24 de junho.

Nadai, Eva e Maeder, Christoph (2009) "Contours of the Field(s): Multi-sited Ethnography as a Theory-driven Research Strategy for Sociology", in Mark-Anthony Falzon (ed.), Multi-sited Ethnography: Theory, Praxis and Locality in Contemporary Research. Farnham: Ashgate, 233-250.

Ó Riain, Seán (2009), "Extending the Ethnographic Case Study”, in David Byrne e Charles C. Ragin (orgs.), The SAGE Handbook of Case-Based Methods. London: Sage, 289-306.

ODPM - Office of the Deputy Prime Minister (2005), Local Strategic Partnerships: Shaping their future: A consultation paper. London: ODPM.

Osborne, Stephen P. (2010), The New Public Governance? Emerging Perspectives on the Theory and Practice of Public Governance. Abingdon: Routledge. 
Phillips, Susan D.; Smith, Steven Rathgeb (orgs.) (2011), Governance and Regulation in the Third Sector. Abingdon: Routledge.

Polizzi, Emanuele (2012), "Building Social Policies with Civil Society Actors. Area Plans and Participation in Milan", in Emanuela Bozzini e Bernard Enjolras (orgs.), Governing Ambiguities: New Forms of Local Governance and Civil Society. Baden-Baden: Nomos, 108-120.

Ragin, Charles C. (1992). "'Casing' and the Process of Social Inquiry”, in Charles C. Ragin e Howard S. Becker (orgs.), What is a Case?: Exploring The Foundations of Social Inquiry. New York: Cambridge University Press, 217-226.

Renda, Andrea; Schreffler, Lorna (2006), Public Private Partnerships. Models and Trends in the European Union, Bruxelas [EU Paper IP/A/IMCO/NT/2006-02].

Rhodes, Rod A. W. (2000), "Governance and Public Administration", in Jon Pierre (org.), Debating Governance: Authority, Steering, and Democracy. Oxford: Oxford University Press, 54-90.

Rodrigues, Fernanda; Stoer, Stephen (2001), "Partnership and Local Development in Portugal”, in Mike Geddes e John Benington (orgs.), Local Partnerships and Social Exclusion in the European Union: New Forms of Local Social Governance? London: Routledge, 134-151.

Russel, Hilary (2005), Voluntary and Community Sector Engagement in Local Strategic Partnerships. National Evaluation of Local Strategic Partnerships. London: ODPM.

Schaap, Linze (2007), "Closure and Governance”, in Eva Sørensen e Jacob Torfing (orgs.), Theories of Democratic Network Governance. New York: Palgrave, 111-132.

Seidl, David (2005), “The Basic Concepts of Luhman's Theory of Social Systems”, in Kai Helge Becker e David Seidl (orgs.), Niklas Lubmann and Organization Studies. Copenhaga: Liber \& Copenhagen Business School Press, 21-53.

Seidl, David; Becker, Kai Helge (2006), "Organizations as Distinction Generating and Processing Systems: Niklas Luhmann's Contribution to Organization Studies”, Organization, 13(1), 9-35.

Schofield, Janet Ward (2000), "Increasing the Generalizability of Qualitative Research", in Roger Gomm, Martyn Hammersley e Peter Foster (orgs.), Case Study Method: Key Texts, Key Issues. London: Sage, 69-97.

Sørensen, Eva; Torfing, Jacob (2007), "Introduction: Governance Network Research: Towards a Second Generation”, in Eva Sørensen e Jacob Torfing (orgs.), Theories of Democratic Network Governance. Basingstoke: Palgrave Macmillian, 1-24.

Sullivan, Helen C.; Skelcher, Chris (2002), Working Across Boundaries. Basingstoke: Palgrave. 
